\title{
Simplified Transient Hot-Wire Method for Effective Thermal Conductivity Measurement in Geo Materials: Microstructure and Saturation Effect
}

\author{
B. Merckx, ${ }^{1,2}$ P. Dudoignon, ${ }^{1}$ J. P. Garnier, ${ }^{3}$ and D. Marchand ${ }^{2}$ \\ ${ }^{1}$ HYDRASA Laboratory, UMR 6269, Poitiers ENSIP, 40, Avenue du Recteur Pineau, 86022 Poitiers, France \\ ${ }^{2}$ Etude Recherches Matériaux, 4, rue Carol Heitz-Bat B, Centre Régional d'Innovation du Biopôle, 86000 Poitiers, France \\ ${ }^{3}$ Equipe Electrofluidique, PPRIMME Institut, University of Poitiers, ENSIP, 40, Avenue du Recteur Pineau, 86022 Poitiers, France
}

Correspondence should be addressed to B. Merckx, benoit.merckx@univ-poitiers.fr

Received 5 August 2011; Revised 4 January 2012; Accepted 16 February 2012

Academic Editor: Jean-Herve Prevost

Copyright ( 92012 B. Merckx et al. This is an open access article distributed under the Creative Commons Attribution License, which permits unrestricted use, distribution, and reproduction in any medium, provided the original work is properly cited.

\begin{abstract}
The thermal conductivity measurement by a simplified transient hot-wire technique is applied to geomaterials in order to show the relationships which can exist between effective thermal conductivity, texture, and moisture of the materials. After a validation of the used "one hot-wire" technique in water, toluene, and glass-bead assemblages, the investigations were performed (1) in glassbead assemblages of different diameters in dried, water, and acetone-saturated states in order to observe the role of grain sizes and saturation on the effective thermal conductivity, (2) in a compacted earth brick at different moisture states, and (3) in a limehemp concrete during 110 days following its manufacture. The lime-hemp concrete allows the measurements during the setting, desiccation and carbonation steps. The recorded $\Delta T / \ln (t)$ diagrams allow the calculation of one effective thermal conductivity in the continuous and homogeneous fluids and two effective thermal conductivities in the heterogeneous solids. The first one measured in the short time acquisitions $(<1 \mathrm{~s})$ mainly depends on the contact between the wire and grains and thus microtexture and hydrated state of the material. The second one, measured for longer time acquisitions, characterizes the mean effective thermal conductivity of the material.
\end{abstract}

\section{Introduction}

The thermal and hydric transfers in geomaterials are fundamental phenomena which can govern firstly the comfort in buildings and residences and secondly the durability of the materials. The microclimatic simulations of the hygrometric and thermal conditions prevailing in the building interiors need the estimation of the wall material characteristics: moisture and effective thermal conductivity face to the outer climatic changes. In fact, the thermal and hydric conductivities are intrinsic properties of the materials. The heat transfers mainly depend on the frequency of grain contacts, size of pores, and air-water ratio infilling the porosity. The moisture transfers mainly depend on the connectivity associated to the meso-to-micro porosity distribution. The development and implementation of "ecomaterials" for building have to demonstrate their ecologic qualities both by their productions and building techniques and also by their thermal and hydric insulation properties. In this "ecomaterial" domain, the earth material and concretes using plant fibers as aggregates are more and more used. Their uses are governed by their mechanical and thermal properties, that is, minimum of mechanical resistance face to the construction necessities and insulation or heat storage abilities. The building techniques of earth material have been largely discussed and normalized. The material cohesion is assumed by the clay mineral matrix often added of some percents of lime or cement. The mechanical resistances are due (1) to the clay matrix cohesion which acts as cement between the sand grains and (2) to the compactness of the clay-sand assemblage which decreases the volume of microporosity. This compactness of the material influences the meso-to-micro porosity distribution. The concretes using plant fibers as aggregates are more and more used with increasing cement-to-lime replacement. These new cement- 
or lime-plant fiber concretes are mainly appreciated for their small effective thermal conductivities. Nevertheless, the thermal conductivities evolve with time according to the structure and saturation index evolutions of the material during the setting, desiccation, and carbonation steps.

The THW method has been progressively developed from 1931 until now $[1,2]$. The method has been particularly advanced these last forty years thanks to very accurate measurements, firstly due to two wires, electric bridges, and small-size devices and secondly due to finite-element simulations [2-5]. The THW method has been used for pure phases as gas, liquids [3,6-11], solids, and melts $[4,5]$. The method was also developed for measurements in electroconducting and in highly corrosive liquids [1215]. Actually, although the guarded hot plate technique is largely used, the transient hot-wire method is extended to the measurement and calculation of the effective thermal conductivity of granular materials [16-19], rocks [20-22], building materials, [23-25], and soils [26-28] via multicaptor or multineedle probes.

The objective of the work is to show that a transient hot-wire (THW) technique, simplified to only one hotwire embedded in geomaterials, allows rapid characterization on the thermal-hydric properties of the building materials which remain realistic face to their heterogeneity. The texture-moisture and thermal effective conductivity relationships are studied firstly on glass-bead assemblages of different diameters in order to demonstrate the role of grain size and saturation index. Secondly, the measurements have been performed in materials used for "ecoconstruction," that is, sand + clay matrix compacted material (compacted earth brick) and lime-hemp concrete in order to follow the evolution of the effective thermal conductivity during their maturation. The technique is tested in such very thin divided and microporous materials taking into account the moisture evolution due to the desiccation and structure evolutions.

\section{Method and Materials}

2.1. Principle of the THW Method. The THW method is a transient dynamic technique based on the measurement of the temperature rise of a linear heat source (hot wire) embedded in the tested material [2, 7-15]. For an infinitely long metallic wire (length/radius ratio $\gg 200$ ) heated at time $t>0$ with a constant heat flux per length unit $q$ and immersed in an infinite homogeneous medium (thermal conductivity and diffusivity: $\lambda$ and $\alpha$, resp.) with uniform initial temperature, the temperature rise $\Delta T(t)$ of the wire is given by (1) [29]:

$$
\Delta T(t)=\left(\frac{q}{4 \cdot \pi \cdot \lambda}\right) \ln \left(\frac{4 \cdot \mathrm{Fo}}{C}\right),
$$

with $C=e^{\gamma}=1.781$ where $\gamma$ is Euler's constant $(\gamma=0.5772)$ and Fo the Fourier number defined by

$$
\text { Fo }=\frac{\alpha \cdot t}{r_{0}^{2}} .
$$

Equation (1) is the analytical solution of an ideal thermal conductive model valid for Fo $\gg 1$ and without convective transfers $[2,3,16]$.
From this ideal model and with known $q$ values, the thermal conductivity can be calculated by

$$
\lambda=\left(\frac{q}{4 \cdot \pi}\right) \cdot\left(\frac{d T}{d(\ln t)}\right)^{-1},
$$

where $d T / d(\ln t)$ is a numerical constant deduced from experimental data for $t$ values which satisfy the condition Fo $\gg 1$.

For practical applications of the THW method, wire and material sample dimensions, among other ideal model hypothesis, are finite and the deviations from the ideal model have then to be evaluated. In fact, the $e(t)$ answer to the wire heating $\Delta T(t)$ resultant of the Joule effect due to an electrical current $i$ is

$$
R(t)=R_{0}\left(1+\beta_{0}\left(T(t)-T_{0}\right)\right),
$$

with $R(t)$ the instantaneous electrical resistance of the wire, $R_{0}$ the resistance of the wire at the $T_{0}$ reference temperature, and $\beta_{0}$ the temperature coefficient of the wire at $22^{\circ} \mathrm{C}$.

Taking into account (3) and (4), the thermal conductivity $\lambda$ may be calculated as follows:

$$
\lambda=\left(\frac{q \cdot R_{0} \cdot \beta_{0} \cdot i}{4 \cdot \pi}\right) \cdot\left(\frac{d e(t)}{d(\ln t)}\right)^{-1},
$$

where $d e(t) / d(\ln t)$ is a numerical constant deduced from the experimental data and from the linear part of the $e(t)=$ $f(\ln (t))$ curve.

2.2. Materials. The heat transfers were measured in assemblages of glass beads and in two geomaterials, that is, a compacted earth brick and a lime-hemp concrete brick. The data (temperature versus time) were recorded using a very pure $\mathrm{Ni}(>99.98 \%)$ wire of $0.125 \mathrm{~mm}$ diameter insert in the glass-bead assemblages or in the earth brick and limehemp brick during the manufacture (Figure 1). The choice of. $125 \mathrm{~mm}$ diameter of the $\mathrm{Ni}$ wire was motivated by the length/diameter ratio $(l / D \gg 200)$ in order to minimize the end effect, and by the necessary wire resistance face to the manufacturing processes. The heat transfers were induced by constant heating using $100 \mathrm{~mA}$ or $300 \mathrm{~mA}$ current. The current generator has to be very precise. It is a Keithley 2400 (precision of $10^{-6} \mathrm{~A}$ ). The nanovoltmeter used is a Keithley 2182 (precision of $10^{-8} \mathrm{~V}$ ). The experiments are driven by a microcomputer equipped with GPIB connections and Labview software. All the measurements are made using the four wire technique.

Successive glass-bead media have been tested. Three types of glass beads Sili S, SL, and M are used. They differ by weak differences in chemical compositions and associated densities (Table 1). Each bead assemblage is characterized by a grain size range $d-D$ evolving from $1.50-1.70 \mathrm{~mm}$ in diameter to $3.80-4.10 \mathrm{~mm}$ for the type $\mathrm{M}$, from 0.40 $0.60 \mathrm{~mm}$ to $3.75-4.50 \mathrm{~mm}$ for the type S, and from 0.50 $0.80 \mathrm{~mm}$ to $2.50-3.20 \mathrm{~mm}$ for the type SL. In spite of the differences in the $d-D$ ranges, the porosity of the successive dead assemblages shows small differences that is, 0.37 , 0.39 , and 0.39 mean porosities for the M, S, and SL bead 


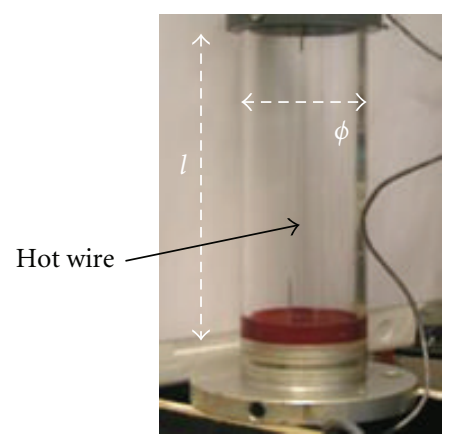

(a)

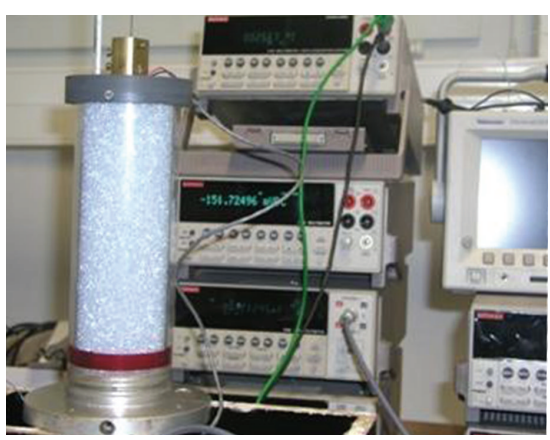

(b)

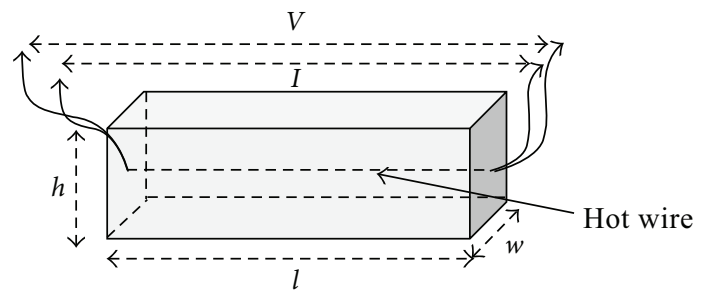

(c)

Figure 1: Details of the Transient Hot-Wire device. (a) Cylindrical cell used for the glass-bead assemblages. (b) Cylindrical cell filled by the beads and Keithley current generator and nanovoltemeter. (c) Schematic representation of the earth brick and lime-hemp brick instrumentation $(l=29.5 \mathrm{~cm}, h=9.5 \mathrm{~cm}, w=14 \mathrm{~cm})$.

assemblages, respectively. To make evident the effect of saturation, the 2.8-3.4 mm glass-bead medium has also been tested saturated with water and acetone. All the glass-bead media have been tested in dried state. The dimensions of the cylindrical cell filled by the glass beads are $19.8 \mathrm{~cm}$ height $(l)$ and $7 \mathrm{~cm}$ diameter $(\varnothing)$ (Figures $1(\mathrm{a})$ and $1(\mathrm{~b})$ ).

The compacted earth brick is made by mechanical compression of earth plus sand mixture added of 5\% lime. In weight percentage, the composition of the compacted brick is $62 \%$ earth, $28 \%$ sand, $5 \%$ lime, and $5 \%$ water. The dimensions of the bricks are $29.5 \mathrm{~cm}$ length, $14 \mathrm{~cm}$ width, and $9.5 \mathrm{~cm}$ height (Figure 1(c)). The mineralogy of sand is quartz dominant, feldspars, and accessory Fe oxides. The mineralogy of the clayey fraction in earth is Illite, Kaolinite, and Smectite. The effective thermal conductivity is measured in the compacted brick from its initial $17 \%$ of gravimetric water content to $3 \%$ of residual water content after 110 days
TABLE 1: Diameter ranges $(d-D)$, mean diameter, glass bead density and porosity of the glass bead assemblages for the M, S, and SL glass beads.

\begin{tabular}{lccc}
\hline $\begin{array}{l}d-D \\
\text { ranges }\end{array}$ & $\begin{array}{c}\text { Mean } \\
\text { diameter }\end{array}$ & $\begin{array}{c}\text { Bead } \\
\text { density }\end{array}$ & Porosity \\
\hline $1.50-1.70$ & 1.50 & Type M & \\
$1.90-2.30$ & 2.00 & 2.54 & 0.38 \\
$2.40-2.70$ & 2.50 & 2.50 & 0.37 \\
$2.70-3.10$ & 2.80 & 2.54 & 0.38 \\
$3.80-4.10$ & 3.90 & 2.50 & 0.36 \\
\hline & & 2.52 & 0.37 \\
$0.40-0.60$ & 0.45 & Type S & \\
$0.70-1.10$ & 0.85 & 2.51 & 0.40 \\
$1.00-1.40$ & 1.10 & 2.52 & 0.39 \\
$1.70-2.20$ & 1.80 & 2.53 & 0.39 \\
$2.50-3.15$ & 2.50 & 2.52 & 0.39 \\
$2.85-3.60$ & 3.00 & 2.51 & 0.38 \\
$3.75-4.50$ & 3.75 & 2.53 & 0.39 \\
& & 2.51 & 0.37 \\
$0.50-0.80$ & 0.71 & Type SL & \\
$0.70-1.05$ & 0.85 & 2.61 & 0.40 \\
$0.90-1.50$ & 1.10 & 2.61 & 0.39 \\
$1.60-2.20$ & 1.80 & 2.59 & 0.39 \\
$2.50-3.20$ & 2.70 & 2.61 &
\end{tabular}

of air drying. The $17 \%$ of water content correspond to a saturation index $\left(I_{\text {sat }}\right)$ of $90 \%$. The $3 \%$ of water content correspond to a saturation index of $15 \%$. The measurements were made daily during the first sixty days and with larger steps (2-3 days) after (Figures 7 and 9).

The lime-hemp concrete is composed of mixture of $25 \mathrm{~kg}$ water, $5.08 \mathrm{~kg}(60 \mathrm{~L})$ hemp (chenevotte), and $35 \mathrm{~kg}$ lime. The weight formulae of the lime-hemp concrete evolve from $38.5 \%$ of water, $7.8 \%$ of chenevotte, and $53.8 \%$ of lime for the fresh concrete. The percentage in weight of lime increases to $76 \%$ for mature concrete. The lime is a Batichanvre Saint Astier (NHL5). The dimensions of the earth and lime-hemp bricks are $29.5 \mathrm{~cm}$ length, $14 \mathrm{~cm}$ width, and $9.5 \mathrm{~cm}$ height (Figure 1(c)).

The heat transfer measurements are represented in $\Delta T\left({ }^{\circ} \mathrm{C}\right)$ versus $\ln (t)$ diagrams (Figures 2 and 3 ). Two types of $\Delta T\left({ }^{\circ} \mathrm{C}\right)$ versus $\ln (t)$ curves are obtained: the "one-slope" curve characteristic of a continuous wire-medium contact observed for liquids (Figure 2), and the "two-slopes" curves observed for the granular media (Figure 3). For the glass beads and the earth brick, the "two-slopes" $\Delta T / \ln (t)$ curves accord to two successive steps of temperature increasing characterized by $a_{1}$ and $a_{2}$ slopes, respectively. The $a_{1}$ and $a_{2}$ slopes are used to calculate two associated thermal conductivities $\lambda_{1}$ and $\lambda_{2}$ as follows ((6); Figure 2):

$$
\lambda=\frac{q}{4 \pi a}=\frac{R i^{2}}{l 4 \pi a}
$$




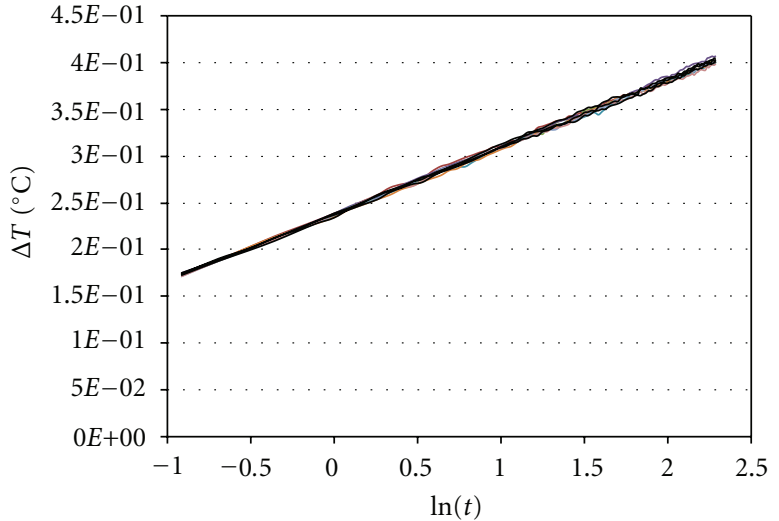

(a)

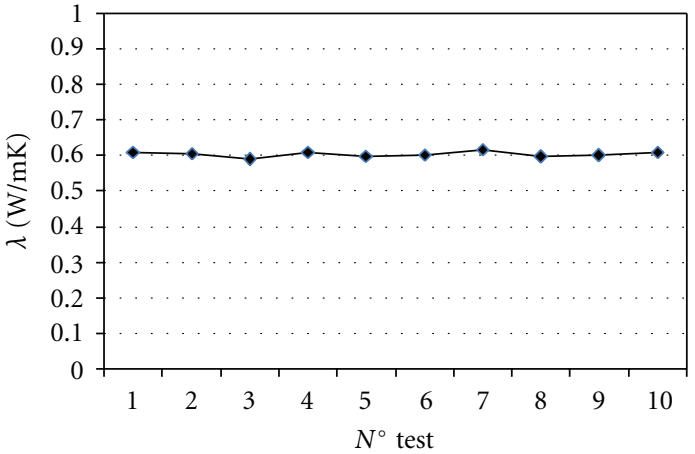

(b)

Figure 2: (a) Superimposition of the $\Delta T / \ln (t)$ curves for 10 successive measurements in water $\left(22^{\circ} \mathrm{C}\right)$. (b) Evolution of the water $\lambda$ measured: $\lambda_{\text {water }}=0.602 \mathrm{~W} / \mathrm{mK}$ with $0.008 \mathrm{~W} / \mathrm{mK}$ standard deviation.

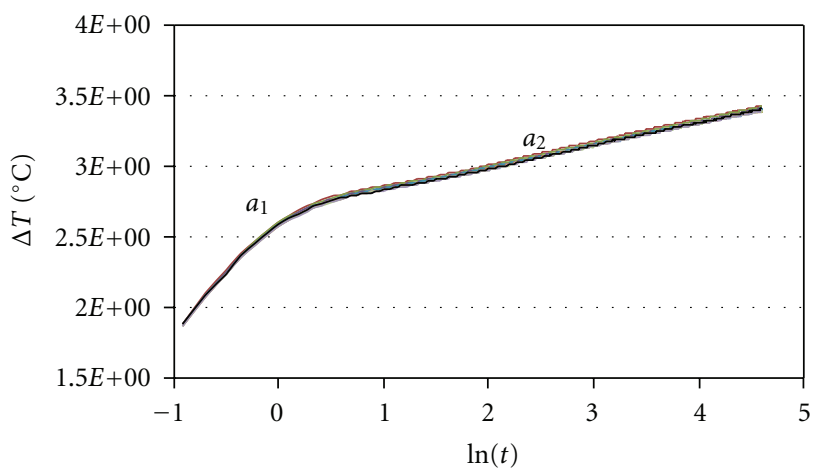

(a)

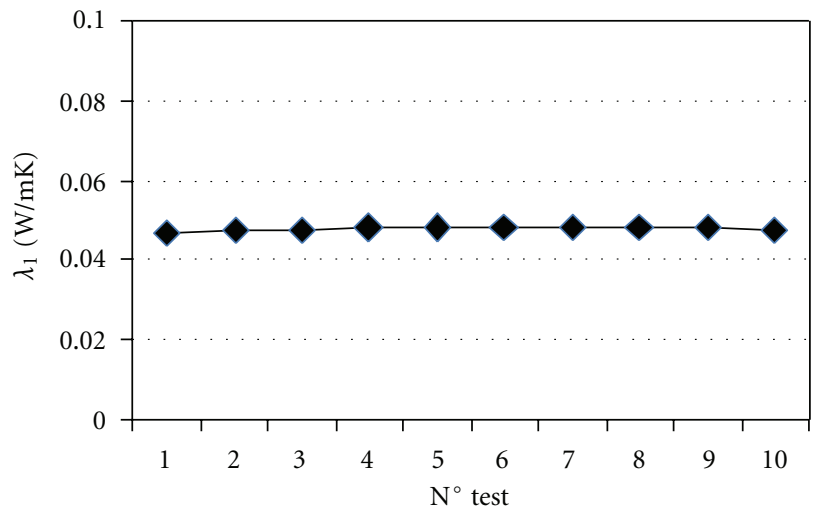

(b)

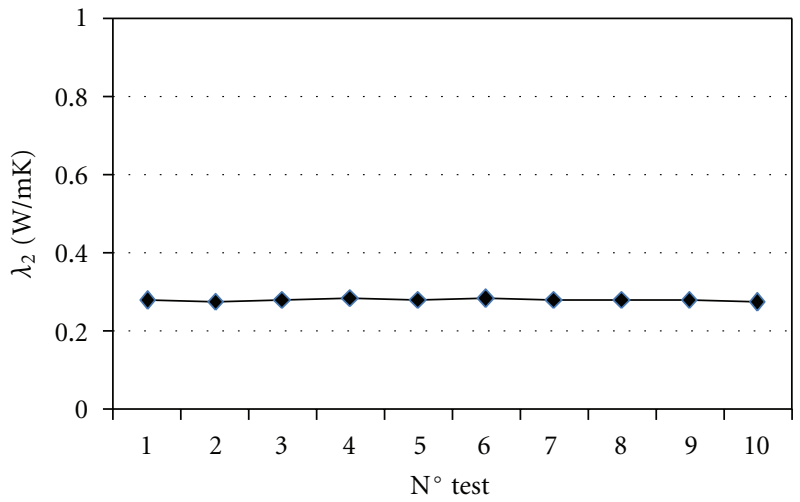

(c)

Figure 3: (a) Superimposition of the $\Delta T / \ln (t)$ curves for 10 successive measurements on $2 \mathrm{~mm}$ diameter glass beads, (b, c) evolution of the measured $\lambda_{1}$ and $\lambda_{2}: \lambda_{1}=0.048 \mathrm{~W} / \mathrm{mK}$ with $0.001 \mathrm{~W} / \mathrm{mK}$ standard deviation, $\lambda_{2}=0.277 \mathrm{~W} / \mathrm{mK}$ with $0.004 \mathrm{~W} / \mathrm{mK}$ standard deviation.

with $a$ the curve slope $(a=\Delta T / \Delta \ln (t)), R$ the electrical resistance of the wire, $i$ the current intensity, $l$ the wire length.

This one hot-wire probe was firstly validated by measurements in water and toluene $\left(22^{\circ} \mathrm{C}\right)$. Ten successive measurements give water and toluene thermal conductivities of $0.602 \mathrm{~W} / \mathrm{mK}$ and $0.1313 \mathrm{~W} / \mathrm{mK}$, respectively, in good agreement with bibliographic data [6]. The ten successive measurements give a standard deviation of $0.008 \mathrm{~W} / \mathrm{mK}$ for the water and $0.002 \mathrm{~W} / \mathrm{mK}$ for the toluene. These ones are equivalent to $1.33 \%$ and $1.5 \%$ and argue for a good repeatability of the measurements (Figure 2). Repeatability tests have also been made on a glass-bead assemblage (M $2 \mathrm{~mm}$ 


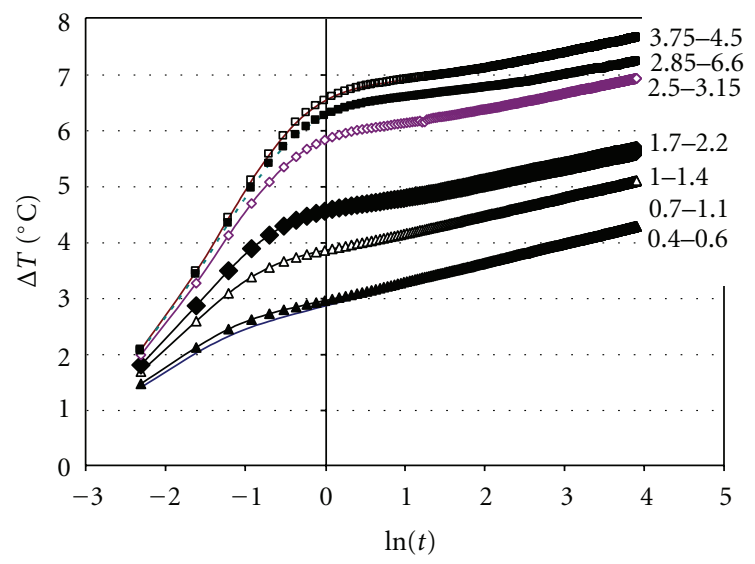

Figure 4: Example of the evolution of the slopes $\left(a_{1}, a_{2}\right)$ of the $\Delta T / \ln (t)$ curves for the successive $S$ glass-bead assemblages. The wire temperature increase was measured using a $300 \mathrm{~mA}$ current.

diameter). The results give $0.048 \mathrm{~W} / \mathrm{mK}$ with a $0.001 \mathrm{~W} / \mathrm{mK}$ standard deviation $(2 \%)$ for $\lambda_{1}$, and $0.277 \mathrm{~W} / \mathrm{mK}$ with $0.004 \mathrm{~W} / \mathrm{mK}$ standard deviation (1.44\%) for $\lambda_{2}$ (Figure 3).

The short time $a_{1}$ slope is characteristic of the noncontinuous wire-medium contact $[30,31]$. For the measurement of thermal conductivity of solids, this contact artifact is often reduced by the addition of a continuous thin layer of transition material as gel, for example $[4,5]$. In fact, in this work, we try to use this $a_{1}$ slope to get characteristics on the texture and saturation index of our granular materials.

The precision of the measurements is influenced by many sets. The precisions of the generator $\left(10^{-6} \mathrm{~A}\right)$ and of the nanovoltmeter $\left(10^{-8} \mathrm{~V}\right)$ minimize a cumulate error on the $\lambda$ measurement which is inferior to $0.01 \%$. Estimating an error of wire length measurement of $0.5 \mathrm{~mm}$, the induced error of $\lambda$ measurement is $0.5 \%$. The end effect error can be calculated following Knibbe's equation [32] taking into account the wire radius/length ratio, the material/wire thermal conductivities, and material diffusivity. Using $125 \mu \mathrm{m}$ diameter $\mathrm{Ni}$ wire of $19.8 \mathrm{~cm}$ in the glass-bead assemblages and $29.5 \mathrm{~cm}$ length in the earth and lime brick, the errors are $1.5 \%, 0.6 \%$, and $1.2 \%$ respectively. Taking into account all these sources of error, the cumulated one is inferior to $3 \%$.

\section{Results}

3.1. Glass Beads. For the glass-bead materials, all the $\Delta T / \ln (t)$ curves show the same features: a first rapid $\Delta T$ increase in short time $(<1 \mathrm{~s})$ and slow $\Delta T$ increase for time $>1 \mathrm{~s}$ (Figure 4). These two domains are characterized by two $a_{1}$ and $a_{2}$ slopes, respectively. In the short-time domain, $a_{1}$ increases when the bead diameter increases. In fact, the $a_{1}$ slope depends on the density of bead contacts with the wire. The associated $\lambda_{1}$ evolves from $0.11 \mathrm{~W} / \mathrm{mK}$ to $0.038 \mathrm{~W} / \mathrm{mK}$. It can be expressed as a function of the bead diameter $(\mathrm{mm})$ as follows ((7); Figure 5(a)):

$$
\lambda_{1}=0.08 D^{-0.5}
$$

TABLE 2: Thermal conductivity $(\lambda)$ of the glass, air, acetone and water.

\begin{tabular}{lc}
\hline Medium & $\lambda(\mathrm{W} / \mathrm{mK})$ \\
\hline air & 0.025 \\
acetone & 0.16 \\
water & 0.60 \\
glass & 1.05 \\
\hline
\end{tabular}

TABLE 3: Evolution of the $\lambda_{1}$ and $\lambda_{2}$ for the different dried and saturated states of the glass bead assemblages. Air saturated for 0.45 to 3.0 mean diameters, acetone, and water saturated for $3.0 \mathrm{~mm}$ mean diameter, Maxwell, and Ktupiczka calculations [16].

\begin{tabular}{lcccc}
\hline Medium & $\begin{array}{c}\lambda_{1} \\
(\mathrm{~W} / \mathrm{mK})\end{array}$ & $\begin{array}{c}\lambda_{2} \\
(\mathrm{~W} / \mathrm{mK})\end{array}$ & $\begin{array}{c}\text { Maxwell } \\
\lambda_{2} \\
(\mathrm{~W} / \mathrm{mK})\end{array}$ & $\begin{array}{c}\text { Ktupiczka } \\
\lambda_{2} \\
(\mathrm{~W} / \mathrm{mK})\end{array}$ \\
\hline $\begin{array}{l}\text { Air } \\
\text { saturated } \\
\begin{array}{l}\text { Acetone } \\
\text { saturated }\end{array}\end{array}$ & $0.1-0.04$ & $0.20-0.40$ & 0.20 & 0.18 \\
$\begin{array}{l}\text { Water } \\
\text { saturated }\end{array}$ & 0.85 & 0.64 & 0.63 & 0.48 \\
\hline
\end{tabular}

For the successive tests performed on the different materials, the $\lambda_{2}$-diameter relationship follows a weak and linear evolution ((8); Figure 4(b)):

$$
\lambda_{2}=0.094 D+0.18 \text {. }
$$

The two obtained $\lambda_{1}$ and $\lambda_{2}$ characterize the "microstructural" and the effective thermal conductivities of the bead assemblages, respectively. The "microstructural" effect is reached thanks to the $0.125 \mathrm{~mm}$ wire diameter. In order to quantify the influence of the porosity saturation the measurements were performed on the dried "air saturated," acetone-saturated and water-saturated material (Tables 2 and 3 ).

The measurements for the different saturation states were made on the $2.8-3.4 \mathrm{~mm}$ diameter glass-bead assemblages. Three types of $\Delta T / \ln (t)$ curves were obtained (Figure 6; Table 3):

(i) the curve characteristic of the dried bead assemblage with the two successive $\lambda_{1}$ and $\lambda_{2}$ characteristics of the microstructure and of the whole material,

(ii) a very flat curve two slope curve for the acetone saturation,

(iii) a straight line for the water saturation.

The $\lambda_{2}$ measured in our glass-bead assemblages accord with the data of Kohout et al. [33] obtained on glass beads of $200 \mu \mathrm{m}$ diameters with glass thermal conductivity of $0.80 \mathrm{~W} / \mathrm{mK}$ and an assemblage porosity of 0.39 . He obtained an effective thermal conductivity increasing from $0.15 \mathrm{~W} / \mathrm{mK}$ in dried state to $0.73 \mathrm{~W} / \mathrm{mK}$ in water-saturated state. For similar conditions, the effective thermal conductivities calculated with the Maxwell model give $0.175 \mathrm{~W} / \mathrm{mK}$ and 


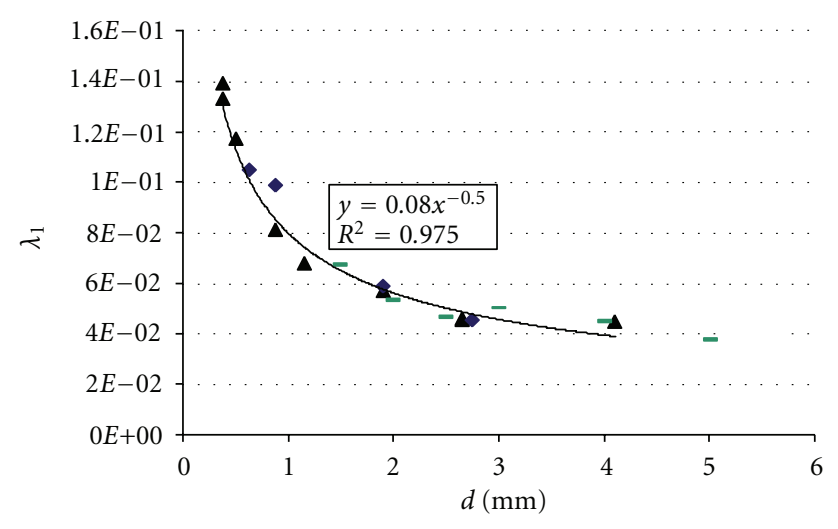

(a)

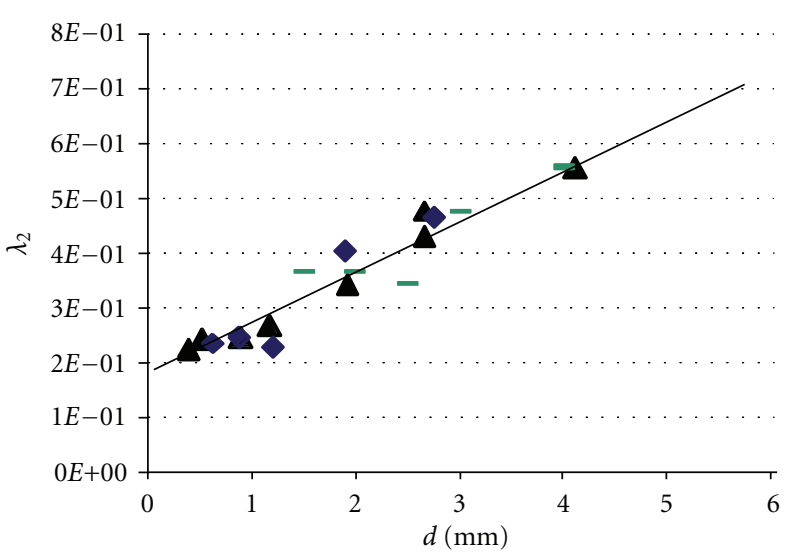

$\Delta$ Type S

Type SL

- Type M

(b)

FIGURE 5: Representation of the $\lambda_{1}$ (a) and $\lambda_{2}$ (b) evolutions versus bead diameters for the 3 types of glass beads S, SL, and M.

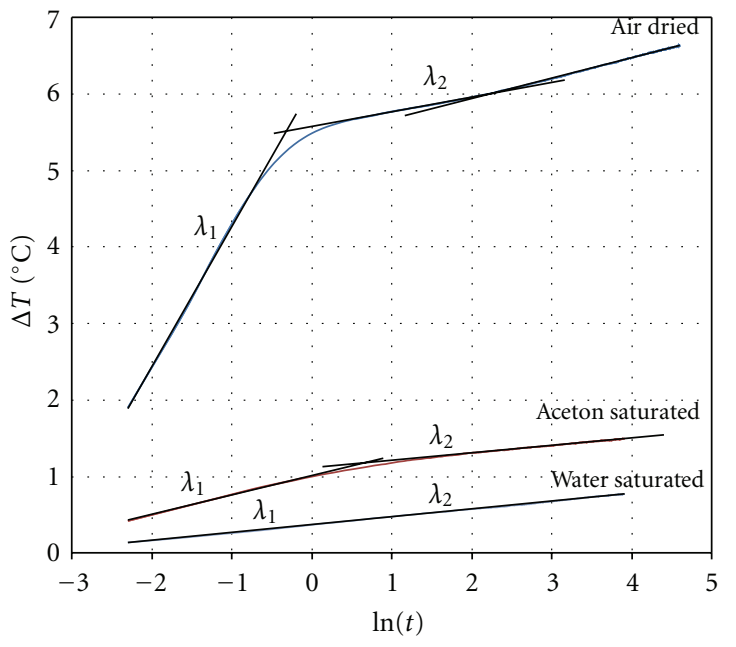

Figure 6: Evolution the $\Delta T / \ln (t)$ curves for 2.8-3.4 mm glass beads in dried, acetone and water saturated states. The shift down of the $\Delta T / \ln (t)$ curves due to the saturation accords with the difference between the thermal conductivities of the $\operatorname{air}(\lambda=0.025 \mathrm{~W} / \mathrm{mK})$, acetone $(\lambda=0.164 \mathrm{~W} / \mathrm{mK})$ and pure water $(\lambda=0.60 \mathrm{~W} / \mathrm{mK})$.

$0.815 \mathrm{~W} / \mathrm{mK}$, respectively [16]. This $\lambda_{2}$ increase according to the saturation index holds also with the Jougnot and Revil results [20] and with the Maxwell and Ktupiczka simulations [16, Table 3].

3.2. Compacted Earth Brick. The thermal conductivities were measured during the 110 days of the brick desiccation. The manufacturing of the earth brick by mechanical compression induced a quite saturated material initially characterized by a saturation index $\left(I_{\text {sat }}\right)$ of $90 \%$. The progressive desiccation causes the simultaneous decrease of the water content and saturation index, from 17 to $3 \%$ and 90 to $15 \%$, respectively (Figure 7).

For this material, only one brick and, consequently, only one texture was tested. The sand grains are coated by the earth clay material. In fact, the clay-to-sand skeleton and the small initial porosity of the compacted material have limited the shrinkage phenomenon. Thus, the porosity may be counted as constant during the desiccation and mainly assumed by the clay matrix microporosity. The scanning electronic microscope confirms this microstructure of the compacted brick. The clay matrix is very compact. All the porosity is constituted of microporosity disseminated between the clay particles and almost micropores have sizes lower than $20 \mu \mathrm{m}$ (Figure 8).

Nevertheless, the $\Delta T / \ln (t)$ curves show evolutions from saturated to unsaturated states which are similar to the glass-bead assemblage ones, that is, a first step of rapid $\Delta T$ increase in short time $(<1 \mathrm{~s})$ and a second one of slow $\Delta T$ increase for time $>1 \mathrm{~s}$. The successive $\Delta T / \ln (t)$ curves are only dependent of the water content and the saturation index. In these conditions, for invariant texture of the material, the evolutions of $a_{1}$ and $a_{2}$ during the drying period characterize the decrease of moisture. The first $\Delta T / \ln (t)$ curves recorded during the first week show quite flat patterns. On the contrary, the curves recorded at the end of the drying period (110 days) show clearly the two different $a_{1}$ and $a_{2}$ slopes (Figure 9). The first curves were recorded for saturation index near $90 \%$ and the last measurement series were performed for saturation index of $15 \%$. This evolution of the $\Delta T / \ln (t)$ curve patterns has consequences on the calculated $\lambda_{1}$ thermal conductivity (Figures 10 and 11): drastic decrease of $\lambda_{1}$ for high water content and associated high $I_{\text {sat }}(50$ to $90 \%)$, and weak $\lambda_{1}$ decrease for $I_{\text {sat }}<50 \%$. The $\lambda_{2}$ is quite constant whatever the water content is.

The evolutions of $\lambda_{1}$ and $\lambda_{2}$ measured on the earth brick show parallel decrease from the saturated initial state to 


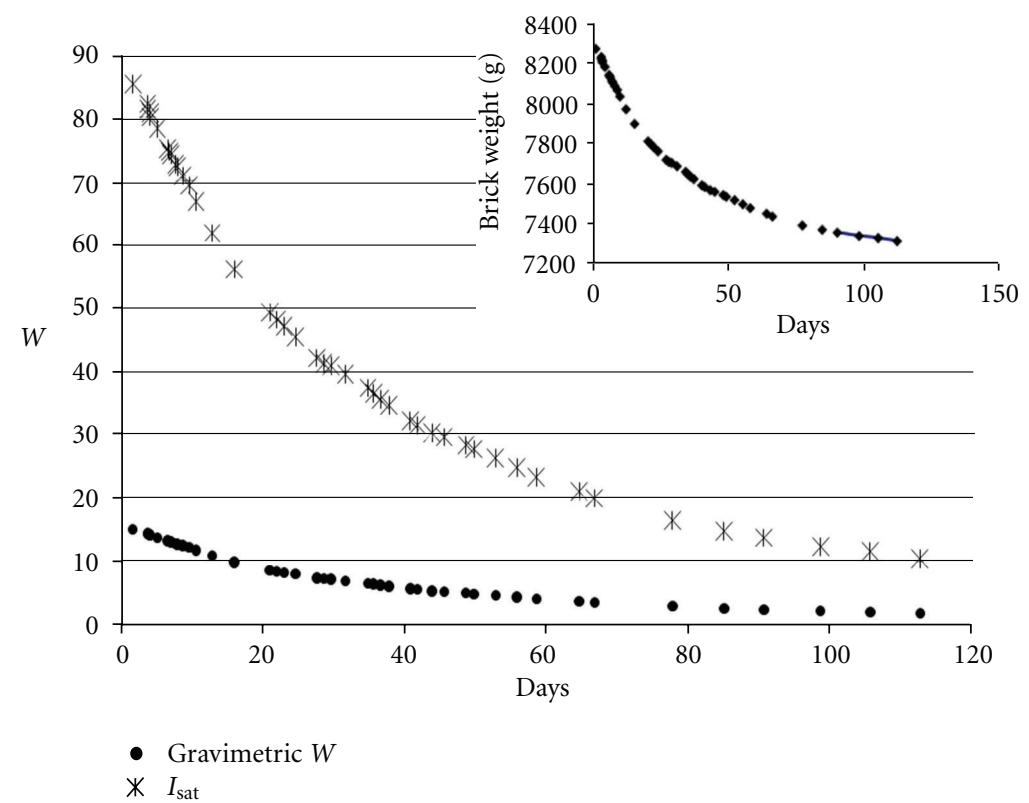

FIgURE 7: Evolution of weight, gravimetric water content $(W)$, and saturation index $\left(I_{\text {sat }}\right)$ of the earth brick during the 110 days of desiccation.

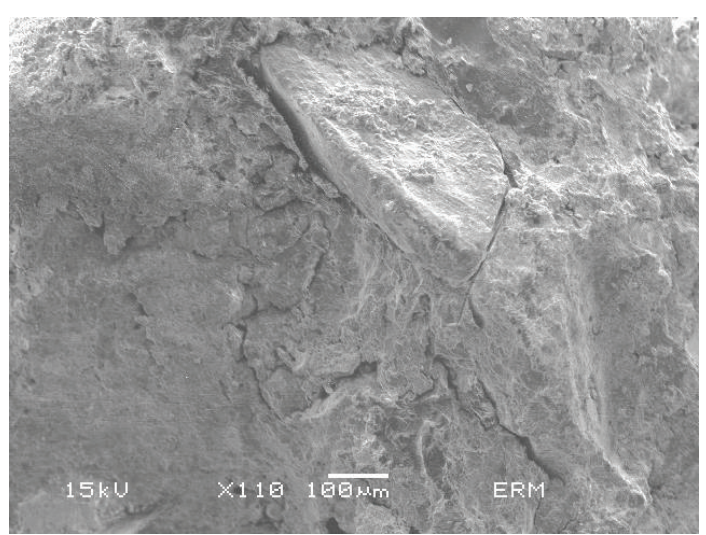

FIGURE 8: SEM microphotography of the earth brick microstructure. The sand grain is isolated inside the compacted clay matrix. The clay matrix appears very compact and homogeneous. The microcracks are consequence of the sampling of the milimetric block from the brick.

the 0.65 saturation index (10 days): that is, from 0.94 to $0.50 \mathrm{~W} / \mathrm{mK}$ and 1.17 to $0.97 \mathrm{~W} / \mathrm{mK}$, respectively. For lower saturation index, the $\lambda_{2}$ values present dispersion around a $0.97 \mathrm{~W} / \mathrm{mK}$ mean value with a standard deviation of $0.05 \mathrm{~W} / \mathrm{mK}(5 \%)$. On the contrary, from the saturated state to low saturation index, the $\lambda_{1}$ values show a continuous decrease from 0.94 to $0.09 \mathrm{~W} / \mathrm{mK}$ following a fitted polynomial curve: $\lambda_{1}=1.6 x^{2}-0.4 x+0.22$, with $x=I_{\text {sat }}\left(R^{2}=0.985\right)$. This $\lambda_{1}$ versus $I_{\text {sat }}$ curve may be used as a good indicator of the material moisture. The comparison with the Cox clay rock of Jougnot and Revil [20] shows similar decrease of the $\lambda$ values from the dried state to saturated one. Nevertheless,

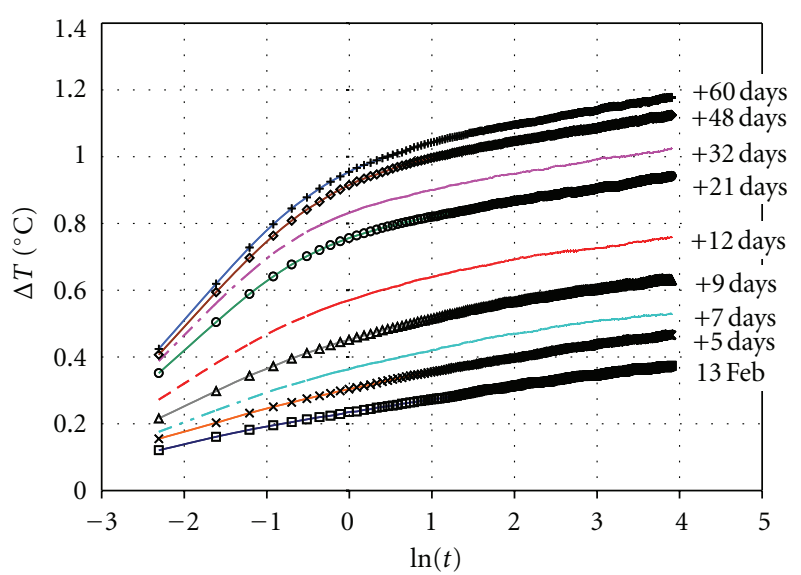

FIGURE 9: Evolution of the $\Delta T / \ln (t)$ curves recorded on the compacted earth brick from 13 February (Feb) to April (+60 days). The shift of the curves from the abscissa to the top of the diagram is due to the desiccation of the clay material. The consequence is the drastic evolution of the $a_{1}$ slope.

its data characterized the effective thermal conductivity of the rock in a low porosity domain (0.14-to-0.16). The 2.0 to $1.41 \mathrm{~W} / \mathrm{mK}$ decrease of $\lambda$ measured in the Cox clay rock is comparable with the 1.17 to $0.95 \mathrm{~W} / \mathrm{mK}$ decrease of $\lambda_{2}$ measured in the 100 to $0.65 I_{\text {sat }}$ domain for our earth brick with a porosity of 0.30 .

3.3. Lime-Hemp Concrete. Two days were necessary to allow the removal of the test piece from the mould. The measurements by the THW method began 2 days after the manufacturing of the lime-hemp concrete. The weight of the test piece was measured from 2 to 110 days. The relative 


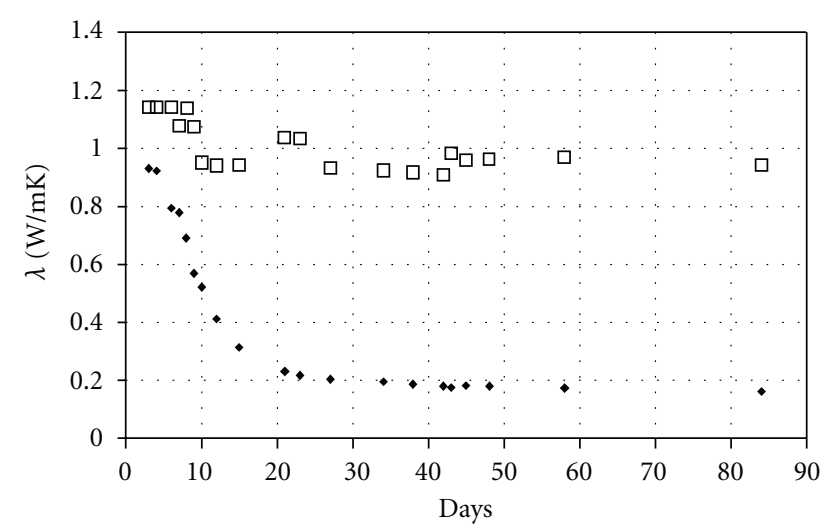

FIgURE 10: Evolution of $\lambda_{1}$ (black lozenges) and $\lambda_{2}$ (white squares) thermal conductivities with time. The $\lambda_{1}$ and $\lambda_{2}$ are calculated from the curve slope measured in the $[-2-1] \ln (t)$ and $[+1+2] \ln (t)$ intervals (Figure 9). According to the drastic $a_{1}$ increase the $\lambda_{1}$ values decrease from 0.9 to $0.2 \mathrm{~W} / \mathrm{mK}$ during the 20 first days. The $\lambda_{2}$ shows dispersive values around $0.97 \mathrm{~W} / \mathrm{mK}$.

lost of weight was $42.10 \%$. It includes the lost of water by desiccation, the hydration, and the carbonation of the lime. The curve of weight versus time shows a "hyperbolic" shape characterized by (Figure 12)

(i) a very high weight lost ( $170 \mathrm{~g} /$ day equivalent to $4.47 \% /$ day) during the 8 first days,

(ii) a weight decrease following a exponential law from 8 to 55 days; that is,

$$
\Delta W=0.23 \exp (-0.45 t)
$$

(iii) a low decrease from 55 to 110 days ( $2 \mathrm{~g} /$ day equivalent to $0.05 \% /$ day).

The successive recorded $\Delta T / \ln (t)$ curves differ from the glass beads and earth brick ones by their staight line shapes. Only the first 0 to 0.3 second measurements do not bring into alignement with the whole data. Nevertheless, the slopes of straight lines increase with the lost of water, following the same trends as the clay-rich compacted brick (Figure 13).

The obtained one-slope $\Delta T / \ln (t)$ curve suggests the subcontinuous lime past-wire contact. According to the straight-line shape of the $\Delta T / \ln (t)$ curves, only one $\lambda$ can be calculated.

The $\lambda$ evolution with time accords to the lost of weigth which may be simplified as a lost of water content. Two steps are evident in the $\lambda / W$ diagram. They are characterized by two linear relationships (Figure 14):

(i) 0 to 20 days; $\lambda=0.74 W+0.36$,

(ii) 20 to 110 days; $\lambda=1.50 \mathrm{~W}+0.29$.

The final $\lambda$ tends to $0.29 \mathrm{~W} / \mathrm{mK}$.

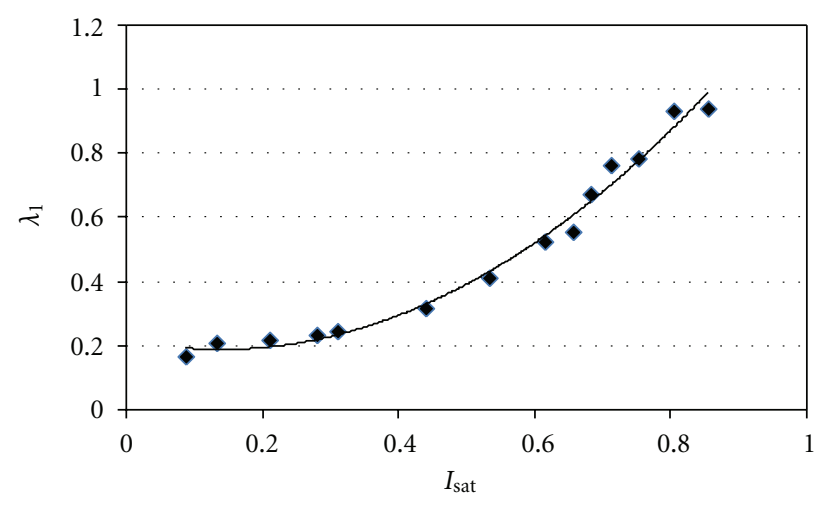

FIGURE 11: Evolution of $\lambda_{1}(\mathrm{~W} / \mathrm{mK})$ thermal conductivity with the saturation index $\left(I_{\text {sat }}\right)$ in the earth brick.

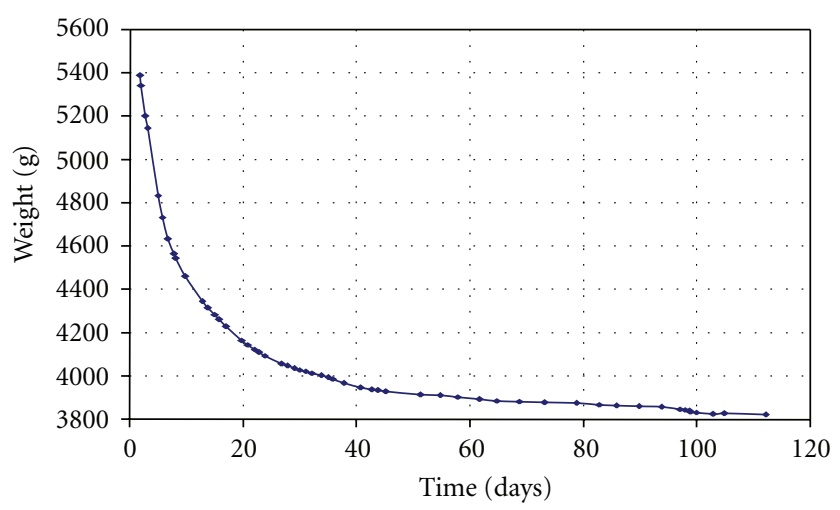

Figure 12: Weight lost of the lime-hemp test piece with time.

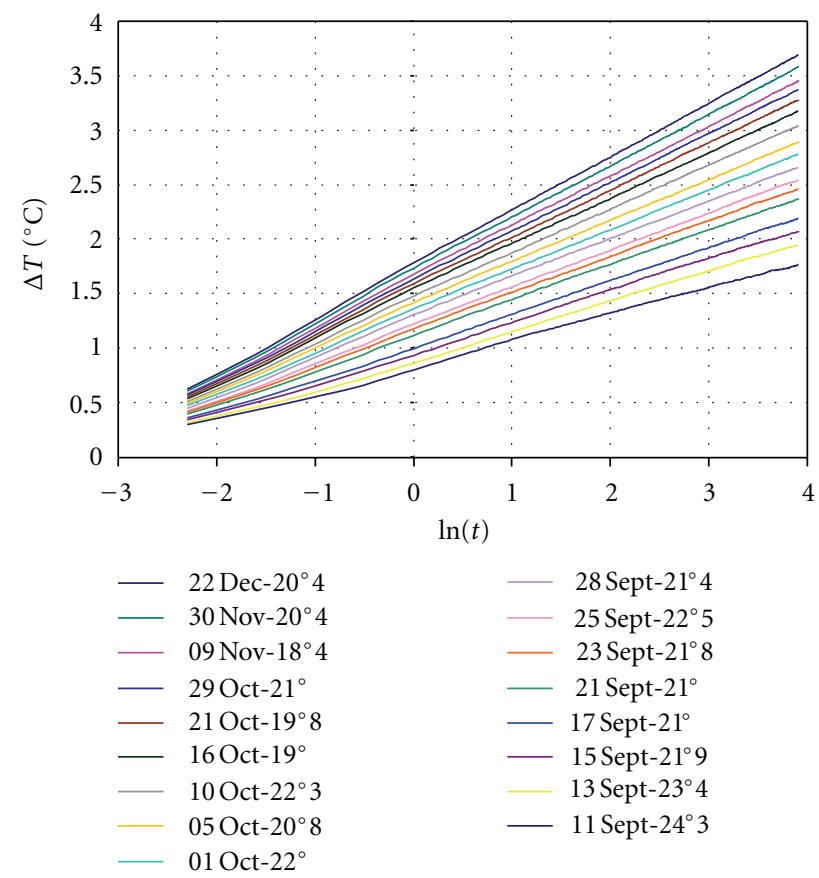

FIGURE 13: Evolutions of the $\Delta T / \ln (t)$ curves with time and, consequently, with the lost of weight. 


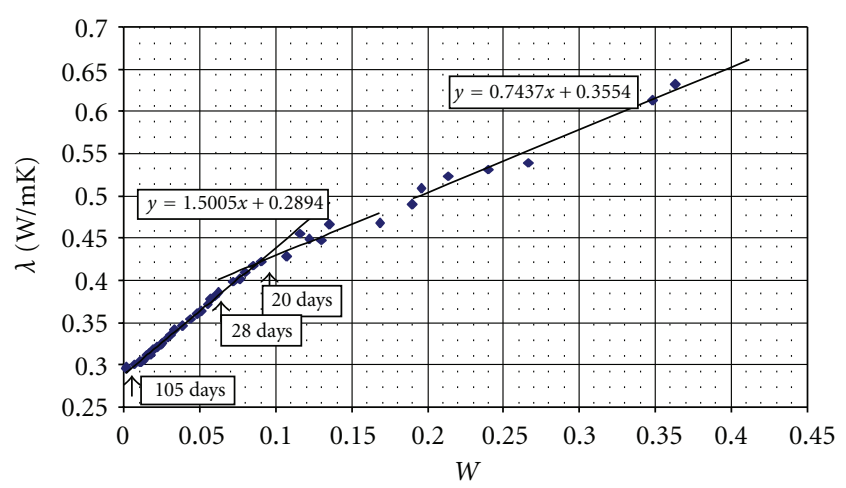

FIGURE 14: Evolution of the thermal conductivity $(\lambda)$ versus water content $(W)$ of the lime-hemp concrete during its setting and hardening.

\section{Discussions and Conclusion}

The investigations, using only one hot wire, in spite of its simplicity and basic aspect face to the recent developments, were tested on granular and geomaterials. Despite the measurement precisions lower than those obtained on pure phases by recent investigations (3\% against 1\% for Assael et al. results; $[4,5])$, this one seems to be overestimated face to the $1.5 \%$ experimental error obtained on the water and toluene. Nevertheless, the following conditions are necessary to minimize the measurement errors:

(i) the diameter/length ratio of wire has to be very small to allow the simplification as infinite linear wire, according to the theory. Nevertheless, it has to be appropriated to the manufacture of the test pieces that is; very low end effect error and sufficient resistance of the embedded wire face to the eventual compression of the material in moulds,

(ii) a very accurate measurement of the wire length and of the associated currents and voltages.

In order to avoid all the artifacts of material surface/wire contact, the hot wires were embedded into the materials during their manufactures. The wire insertion is particularly easy for the glass-bead assemblages and during the earth brick or lime-hemp concrete compaction, and, therefore, for different other types of manufactured geomaterials. The experiments on glass beads show the interest in recording the $\Delta T / \ln (t)$ patterns in short $(<1 \mathrm{~s})$ and long acquisition times. In short times, the $\Delta T / \ln (t)$ patterns allow characterisations on the microstructure and the saturation state of the material. The measurements on the clay dominant material show similar results in spite of the very thin size of particles and associated microporosity. The evolution of the $\lambda_{1}$ coefficient obtained in short times is sufficient to characterize the moisture and saturation index of the material for one knew grain size distribution (Figures 4 and 5). The $\lambda_{2}$ coefficient obtained during the second step of acquisition $(t>1 \mathrm{~s})$ is characteristic of the whole material effective thermal conductivity. In addition, the $\lambda_{1}$ and $\lambda_{2}$ are commensurate with the grain size of the material (Figure 5).
Tested on the lime-hemp concrete from its manufacture to advance desiccation + setting steps (110 days), the method confirms its validity for geomaterials. The $\Delta T / \ln (t)$ curves evolve according to the desiccation + setting advancement. Nevertheless, the $\Delta T / \ln (t)$ curves present straight-line patterns which allow the calculation of only one thermal conductivity characteristic of the whole material. The lack of the first slope, of the $\Delta T / \ln (t)$ curve, equivalent to the "short time" $\lambda_{1}$ results of the continuous coating of the wire by the lime cement.

These preliminary results suggest the possibility of investigation on the relationship which prevails between the microstructure and saturation state of geomaterials and their effective thermal conductivity. The technique may be extended to in situ measurements in walls, soils, and other materials in order to record data on the thermohydric transfers and to be used for the mathematical simulations of the mechanisms.

\section{References}

[1] M. J. Assael, K. D. Antoniadis, and W. A. Wakeham, "Historical evolution of the transient hot-wire technique," International Journal of Thermophysics, vol. 31, no. 6, pp. 1051-1072, 2010.

[2] J. J. Healy, J. J. de Groot, and J. Kestin, "The theory of the transient hot-wire method for measuring thermal conductivity," Physica B+C, vol. 82, no. 2, pp. 392-408, 1976.

[3] "Measurement of the transport properties of fluids," in Experimental Thermodynamics, W. A. Wakeham, A. Nagashima, and J. V. Sengers, Eds., vol. 3, Blackwell Scientific Publications, London, UK, 1991.

[4] M. J. Assael, K. D. Antoniadis, and J. Wu, "New measurements of the thermal conductivity of PMMA, BK7, and Pyrex 7740 up to 450K," International Journal of Thermophysics, vol. 29, no. 4, pp. 1257-1266, 2008.

[5] M. J. Assael, K. D. Antoniadis, K. E. Kakosimos, and I. N. Metaxa, "An improved application of the transient hotwire technique for the absolute accurate measurement of the thermal conductivity of pyroceram 9606 up to $420 \mathrm{~K}$," International Journal of Thermophysics, vol. 29, no. 2, pp. 445456, 2008 .

[6] M. L. V. Ramires, J. M. N. A. Fareleira, C. A. Nieto de Castro, M. Dix, and W. A. Wakeham, "The thermal conductivity of toluene and water," International Journal of Thermophysics, vol. 14, no. 6, pp. 1119-1130, 1993.

[7] J. R. Parsons Jr. and J. C. Mulligan, "Measurement of the properties of liquids and gases using a transient hot-wire technique," Review of Scientific Instruments, vol. 49, no. 10, pp. 1460-1463, 1978.

[8] C. A. Nieto De Castro, J. C. G. Calado, W. A. Wakeham, and M. Dix, "An apparatus to measure the thermal conductivity of liquids," Journal of Physics E, vol. 9, no. 12, article 020, pp. 1073-1080, 1976.

[9] R. A. Perkins, M. L. V. Ramires, and C. A. Nieto De Castro, "Thermal conductivity of saturated liquid toluene by use of anodized tantalum hot wires at high temperatures," Journal of Research of the National Institute of Standards and Technology, vol. 105, no. 2, pp. 255-265, 2000.

[10] R. A. Perkins, M. L. V. Ramires, C. A. Nieto de Castro, and L. Cusco, "Measurement and correlation of the thermal 
conductivity of butane from $135 \mathrm{~K}$ to $600 \mathrm{~K}$ at pressures to 70 MPa," Journal of Chemical and Engineering Data, vol. 47, no. 5, pp. 1263-1271, 2002.

[11] G. Thevenot, J. Saillard, J. P. Maye, and J. P. Garnier, "Cellule de mesure de la conductivité et de la diffusivité thermiques d'un fluide et sonde pour cette cellule," European Patent Office. EP 1724572 A1, 2006.

[12] A. Alloush, W. B. Gosney, and W. A. Wakeham, "A transient hot-wire instrument for thermal conductivity measurements in electrically conducting liquids at elevated temperatures," International Journal of Thermophysics, vol. 3, no. 3, pp. 225235, 1982.

[13] Y. Nagasaka and A. Nagashima, "Absolute measurement of the thermal conductivity of electrically conducting liquids by the transient hot-wire method," Journal of Physics E, vol. 14, no. 12, pp. 1435-1440, 1981.

[14] J. P. Garnier, J. P. Maye, J. Saillard, G. Thévenot, A. Kadjo, and S. Martemianov, "A new transient hot-wire instrument for measuring the thermal conductivity of electrically conducting and highly corrosive liquids using small samples," International Journal of Thermophysics, vol. 29, no. 2, pp. 468-482, 2008.

[15] A. Kadjo, J. P. Garnier, J. P. Maye, and S. Martemianov, "A new transient two-wire method for measuring the thermal diffusivity of electrically conducting and highly corrosive liquids using small samples," International Journal of Thermophysics, vol. 29, no. 4, pp. 1267-1277, 2008.

[16] I. H. Tavman, "Effective thermal conductivity of granular porous materials," International Communications in Heat and Mass Transfer, vol. 23, no. 2, pp. 169-176, 1996.

[17] J. Z. Liang and F. H. Li, "Measurement of thermal conductivity of hollow glass-bead-filled polypropylene composites," Polymer Testing, vol. 25, no. 4, pp. 527-531, 2006.

[18] E. E. Gonzo, "Estimating correlations for the effective thermal conductivity of granular materials," Chemical Engineering Journal, vol. 90, no. 3, pp. 299-302, 2002.

[19] G. K. Batchelor and R. W. O'Brien, "Thermal or electrical conduction through a granular material," Proceedings of the Royal Society of London Series A, vol. 355, no. 1682, pp. 313333, 1977.

[20] D. Jougnot and A. Revil, "Thermal conductivity of unsaturated clay-rocks," Hydrology and Earth System Sciences, vol. 14, no. 1, pp. 91-98, 2010.

[21] C. Gruescu, A. Giraud, F. Homand, D. Kondo, and D. P. Do, "Effective thermal conductivity of partially saturated porous rocks," International Journal of Solids and Structures, vol. 44, no. 3-4, pp. 811-833, 2007.

[22] J. P. Cull, "Thermal conductivity probes for rapid measurements in rock," Journal of Physics E, vol. 7, no. 9, article 026, pp. 771-774, 1974.

[23] M. Stefanidou, M. Assael, K. Antoniadis, and G. Matziaroglou, "Thermal conductivity of building materials employed in the preservation of traditional structures," International Journal of Thermophysics, vol. 31, no. 4-5, pp. 844-851, 2010.

[24] A. Bouguerra, "Temperature and moisture dependence on the thermal conductivity of wood-cement-based composite: experimental and theoretical analysis," Journal Physics D.: Applied Physics, vol. 32, no. 21, pp. 2797-2803, 1999.

[25] A. Bouguerra, A. Ledhem, F. De Barquin, R. M. Dheilly, and M. Quéneudec, "Effect of microstructure on the mechanical and thermal properties of lightweight concrete prepared from clay, cement, and wood aggregates," Cement and Concrete Research, vol. 28, no. 8, pp. 1179-1190, 1998.
[26] K. L. Bristow, "Measurement of thermal properties and water content of unsaturated sandy soil using dual-probe heat-pulse probes," Agricultural and Forest Meteorology, vol. 89, no. 2, pp. 75-84, 1998.

[27] K. L. Bristow, G. J. Kluitenberg, C. J. Goding, and T. S. Fitzgerald, "A small multi-needle probe for measuring soil thermal properties, water content and electrical conductivity," Computers and Electronics in Agriculture, vol. 31, no. 3, pp. 265-280, 2001.

[28] D. A. De Vries and A. J. Peck, "On cylindrical probe method of measuring thermal conductivity with special reference to soils," Australian Journal of Physics, no. 11, pp. 225-271, 1958.

[29] H. S. Carslaw and J. C. Jaeger, Conduction of Heat in Solids, Oxford University Press, London, UK, 1959.

[30] A. Testu, Dispersion thermique dans des milieux granulaires: caractérisation à cour et en proche paroi, thèse, Institut National Polytechnique de Lorraine, Nancy, 2005.

[31] H. Martin, "Low peclet number particle-to-fluid heat and mass transfer in packed beds," Chemical Engineering Science, vol. 33, no. 7, pp. 913-919, 1978.

[32] P. G. Knibbe, "The end-effect error in the determination of thermal conductivity using a hot-wire apparatus," International Journal of Heat and Mass Transfer, vol. 29, no. 3, pp. 463-473, 1986.

[33] M. Kohout, A. P. Collier, and F. Stepanek, "Effective thermal conductivity of wet particle assemblies," International Journal of Heat and Mass Transfer, vol. 47, no. 25, pp. 5565-5574, 2004. 

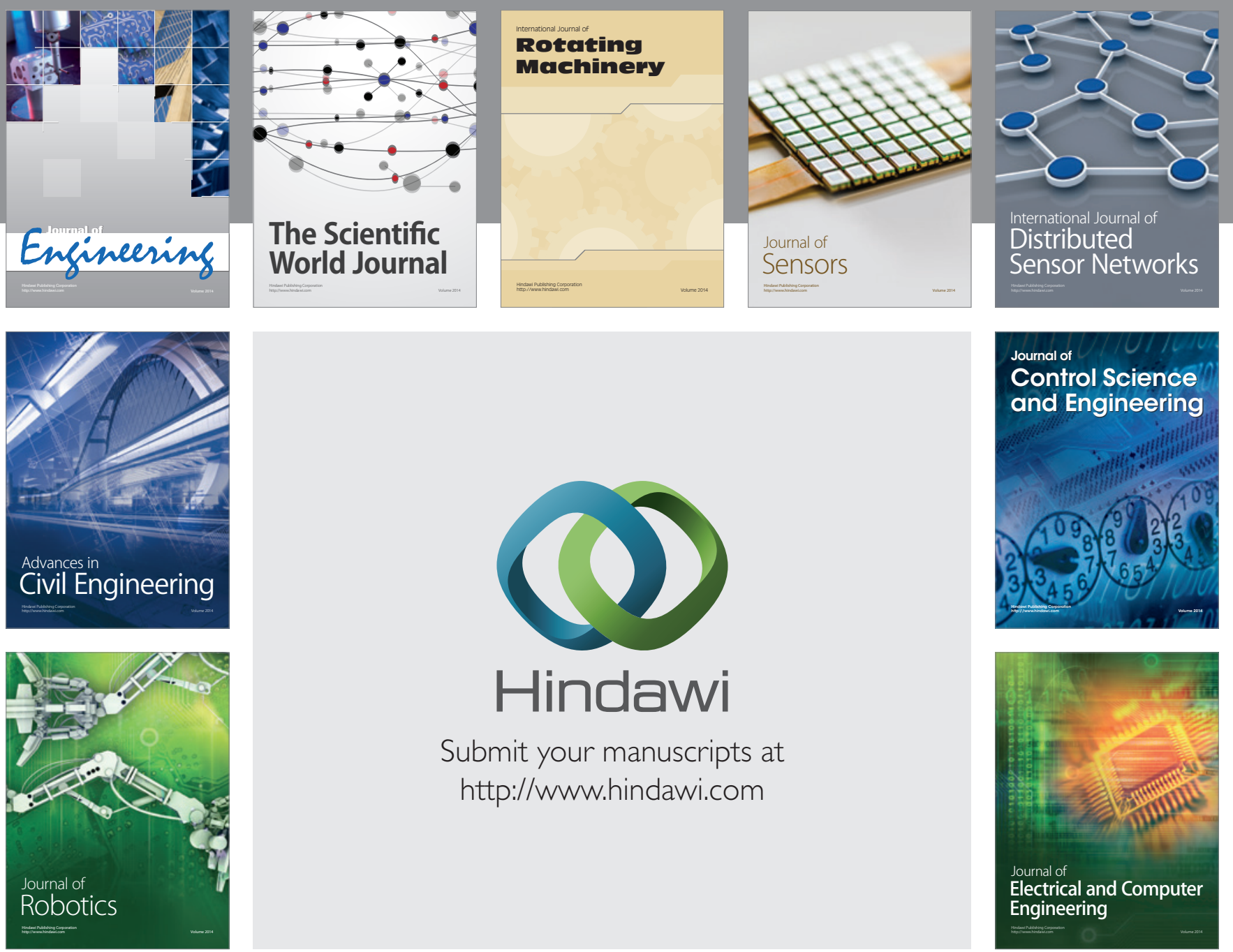

Submit your manuscripts at

http://www.hindawi.com
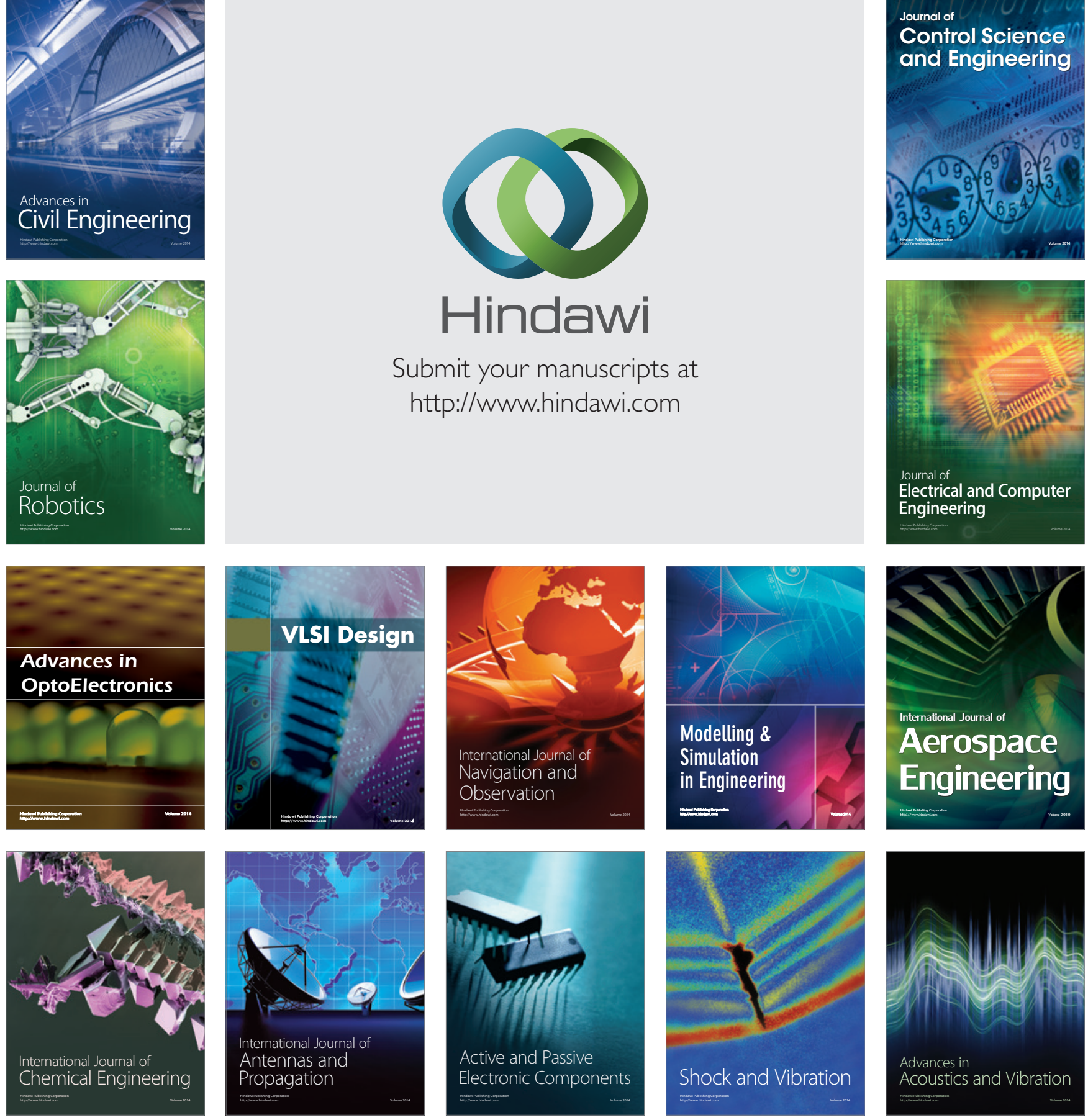